\title{
Yenidoğan Ünitelerinde Çalışan Hemşirelerin Sarılık Tedavisi Konusunda Uygulama Düzeylerinin Değerlendirilmesi
}

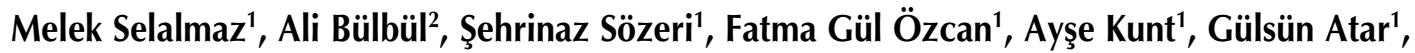 \\ Umut Zübarioğlu ${ }^{3}$, Ebru Türkoğlu Ünal ${ }^{3}$, Sinan Uslu²
}

ÖZET:

Yenidoğan ünitelerinde çalışan hemşirelerin sarılık tedavisi konusunda uygulama düzeylerinin değerlendirilmesi

Amaç: Yenidoğan bebeklerde sarııı tedavisinde verilen sağlık bakım hizmeti hakkında, hemşirelerin uygulama düzeyinin değerlendirilmesi.

Gereç ve Yöntem: Çalışma verileri İstanbul ilinde iki eğitim ve araştırma hastanesi yenidoğan bölümlerinde görevli olan ve çalışmayı kabul eden hemşirelerden elde edildi. Araştırmacılar tarafından deneyimler ve literatür bilgileri doğrultusunda çalışmanın anket formu olușturuldu, etik kurul onayı alındı. Ankette bireyin genel çalışma özellikleri ile birlikte; sarııı̆ın erken tanı, tedavi ve izlemi ile ilgili bilgi düzeyleri değerlendirildi. Eğitim durumunun ve çalışma sürelerinin değişkenler üzerine olan etkileri incelendi. Veriler yüzdelik ve ki-kare testleri ile değerlendirildi.

Bulgular: Çalışma, ankete katılmayı kabul eden 87 yenidoğan hemşiresi ile tamamlandı. Hemşirelerin \%51.7'si lisans mezunu idi. Sarılık ile ilgili eğitim alma oranı \%57.5 sıklığındaydı. Ankette sarılık gelişimi ile ilgili risk faktörlerinin \%79.3, uygun şekilde sarılığın tespit edilmesinin \%58.6, patolojik sarılık tanımının \%73.1, sarılığın klinik bulgularının \%61.3, fototerapi etkinliğini artırma yöntemlerinin \%79.6, fototerapi hemşirelik bakım esaslarının \%52.9, fototerapi yan etkilerinin \%42.6 ve fototerapi esnasındaki uygun beslenme modelinin \%65.6 oranlarında doğru bilindiği belirlendi. Yüksek lisans mezunlarının anne sütü sarıı̆̆ı sendromunu doğru tanımlamada (p:0.05) ve erken anne sütü sarıı̆̆ını bilmede (p:0.018) daha başarılı oldukları saptandı. Yenidoğan bölümünde beş yıldan fazla çalışanlarda fototerapinin yan etkilerini bilme (p:0.039) oranları daha yüksekti.

Sonuç: Hemşirelerin sarılığın klinik bulgularını, sarılık gelişimindeki risk faktörlerini, fototerapinin etkinliğini artırma yöntemlerini ve fototerapi esnasında beslenme yöntemlerini önemli bir oranda doğru olarak bildiği saptandı. Yüksek lisans eğitimi alan veya 5 yıldan daha uzun süre yenidoğan bölümünde çalışan hemşirelerin uygulama bilgilerinin daha yüksek oranda doğru olduğu belirlendi.

Anahtar kelimeler: Yenidoğan, hemşirelik, bakım, fototerapi

ABSTRACT:

The evaluation of the implementation level of nurses working in neonatal intensive care unit in the treatment of neonatal jaundice

Objective: To evaluate the application level of nurses about health care service given at jaundice treatment on newborn babies.

Material and Method : Study data was obtained from nurses who work in neonatal units of two training and research hospitals of i̇stanbul and agreed to participate the study. For this study a questionnaire form established by investigators under the supervision of experties and under the consideration of literature knowledge and approval from ethical committee received. In questionnaire, with general working characteristics of individual, also knowledge level about early diagnosis, treatment and follow up of jaundice evaluated. The impact of educational status and working period on the variables was analysed. Data were analyzed with percentage and chi-square methods.

Results: The study performed with 87 nurses who accepted the questionnaire. Fifty one point seven percent of nurses were university graduates. The receive education rate about jaundice was $57.5 \%$. In questionnaire, the percentage of right knowledge for risk factors about development of jaundice was $79.3 \%$, detection of jaundice properly was $58.6 \%$, the definition of pathologic jaundice was $73.1 \%$, clinical findings of jaundice was $61.3 \%$, the methods for increasing the effectiveness of phototherapy was $79.6 \%$, principles of nursing care for phototherapy was $52.9 \%$, side effects of phototherapy was $42.6 \%$ and proper feeding method during phototherapy was $65.6 \%$. Master graduates were detected more succesfull in correct definition of breast feeding jaundice syndrome (p:0.05) and knowing early breast feeding jaundice (p:0.018). The percentage of knowing the side effects of phototherapy was higher in nurses working more than 5 years in neonatal units (p:0.039). Conclusion: It was detected that the nurses had true knowledge with important proportion about clinical features and risk factors in development of jaundice, methods for increasing the effectiveness of phototherapy and feeding methods during phototherapy. The application knowledge was determined higher correct proportion in nurses who were master graduates or working period more than 5 years in newborn units. Key words: Neonatal, nursing, care, phototherapy

Ş.E.E.A.H. Tıp Bülteni 2015;49(3):195-9

'Uzman Hemșire, Șişli Hamidiye Etfal Eğitim ve Araştırma Hastanesi, Yenidoğan Kliniği, İstanbul - Türkiye

${ }^{2}$ Doçent Doktor, Şişli Hamidiye Etfal Eğitim ve Araştırma Hastanesi, Yenidoğan Kliniği, İstanbul - Türkiye

3Uzman Doktor, Şişli Hamidiye Etfal Eğitim ve Araştırma Hastanesi, Yenidoğan Kliniği, İstanbul - Türkiye

Yazışma Adresi / Address reprint requests to: Ali Bülbül,

Şişli Hamidiye Etfal Eğitim ve Araştırma Hastanesi, Yenidoğan Kliniği, İstanbul - Türkiye

Telefon / Phone: +90-505-265-4425

E-posta / E-mail:

drbulbul@yahoo.com

Geliş tarihi / Date of receipt:

9 Nisan 2015 / April 9, 2015

Kabul tarihi / Date of acceptance:

22 Mayıs 2015 / May 22, 2015 


\section{Giriș}

Yenidoğan sağ lı̆̆ındaki tüm olumlu gelişmelere rağmen günümüzde yenidoğan bebeklerde en sık saptanan hastalıklar grubu içerisinde ilk sırayı yenidoğan sarılığı almaktadır. Yenidoğan sarılığı term bebeklerde \%60-70 oranında, preterm bebeklerde ise \%70-80 oranlarında görülmektedir (1).

Yenidoğan sarılığı hastalık olarak geniş bir yelpaze içerisinde klinik bulgulara neden olmaktadır. Bir yandan masum, kendiliğinden gerileyebilen ve fizyolojik olarak kabul edilen sınırlar içerisinde kalabilirken diğer yandan ciddi bilirubin düzeylerine ulaşarak beyinde kalıcı hasara neden olabilen kronik bilirubin ensefalopatisi (kernikterus) ile sonuçlanabilmektedir (2). Bu nedenle yenidoğan sarılığının uygun şekilde yakın takip edilmesi ve doğru şekilde tedavi edilmesi gerekliliği önemini arttırmaktadır. Yenidoğan sarılığının prognozunu; ailenin eğitim durumu ile birlikte, ailenin sarılık konusunda bilgilendirme durumu, bebeğin sarılık açısından kontrole çağrılma zamanı ve sarılık gelişmesi durumunda yapılması gerekenlerin yazılı olarak kayıt altına alınıp ailelerin yazılı olarak bilgilendirilmesi durumu etkileyebilmektedir (3).

Tedavide uygulayıcı olarak görev alan yenidoğan hemşiresinin özellikle izlemde rolü tartışılamaz konumdadır. Fototerapinin uzaklığı, açık cilt yüzeyinin sağlanması ve fototerapi alan bebeğin beslenmesi bir yana koruyucu olarak göz bandının uygun yerleştirilmesi ve genital organların fototerapiden korunması konusunda yenidoğan hemşiresinin yeterli bilgi ve beceri özelliklerine sahip olması gerekir. Etkili hemşirelik bakımı ile fototerapinin etkisi artırılmakta ve komplikasyonlar en az düzeye indirilmektedir (4).

Bu bilgiler ışığında tanımlayıcı bir araştırma olarak planlanan çalışmamızda yenidoğan kliniğinde en sık yatış nedeni olan yenidoğan sarılığının tedavi ve izlemi ile ilgili olarak hemşirelerin uygulama durumunun belirlenmesi, saptanan verilerin demografik özellikler ile ilişkisinin değerlendirilmesi ve sonuçlar doğrultusunda eğitim planının yapılması hedeflenmiştir.

\section{GEREÇ VE YÖNTEM}

Çalışma Nisan - Mayıs 2013 tarihleri arasında, İstanbul ilinde iki eğitim ve araştırma hastanesinde, kesitsel ve tanımlayıcı olarak yapıldı. Verilerin toplandığı günlerde görevde olan ve araştırmaya katılmayı kabul eden toplam 87 yenidoğan hemşiresi örnekleme alındı. Çalışmaya Şişli Hamidiye Etfal Eğitim ve Araştırma Hastanesi etik onayı (364/2013) alındıktan sonra başlandı.

Verilerin toplanmasında araştırmacılar (iki uzman hemşire ve iki uzman hekim) tarafından konu ile ilgili uzman görüşleri ve literatürde konu ile ilgili bilgiler doğrultusunda geliştirilen anket formu kullanıldı. Ankette bireyin kimlik bilgileri alınmadı. Gönüllülük esasına göre anketi kabul edenler ile görüşme yapıldı. Araştırmacılar tarafından hazırlanan anket formunda 7 soru bireyin demografik özelliklerini, 14 soru ise sarılık, fototerapi uygulamaları ve fototerapi etkinliğini içeren toplam 21 sorudan oluştu. Araştırmacılar ile çalışmayı kabul eden sağlık çalışanları arasında bire bir görüşme sonucunda elde edilen veriler kaydedildi.

\section{Çalışma Grubu}

Yenidoğan bebeklere fototerapi hizmeti veren Yenidoğan Klinikleri ile Çocuk Cerrahisi Kliniklerinde görevli hemşireler çalışmaya alındı.

\section{İstatistik}

Elde edilen veriler SPSS 11.5 programında değerlendirildi. Genel özellikler ve saptanan bulguların oran olarak değerlendirilmesi tanımlayıcı istatistik analiz yöntemi ile yapıldı. Veriler yüzdelik olarak verildi. Verilerin karşılaştırılmasında ki-kare testi uygulandı. $p<0.05$ değeri istatistiksel anlamlı kabul edildi.

\section{BULGULAR}

Çalışma, anketi kabul eden 87 hemşire ile yapıldı. Çalışmanın akış diyagramı Şekil 1'de sunuldu. Çalışmaya katılanların demografik özellikleri Tablo 1'de verildi.

Sarılık gelişimindeki risk faktörlerini tanımlayan sorumuzda; anne-bebek arasında kan grubu uygunsuzluğu (\%93.1), preterm doğum (\%78.2), cilt altı kanama, hematom (\%47.1), ilk 24 saatte sarılık görül- 


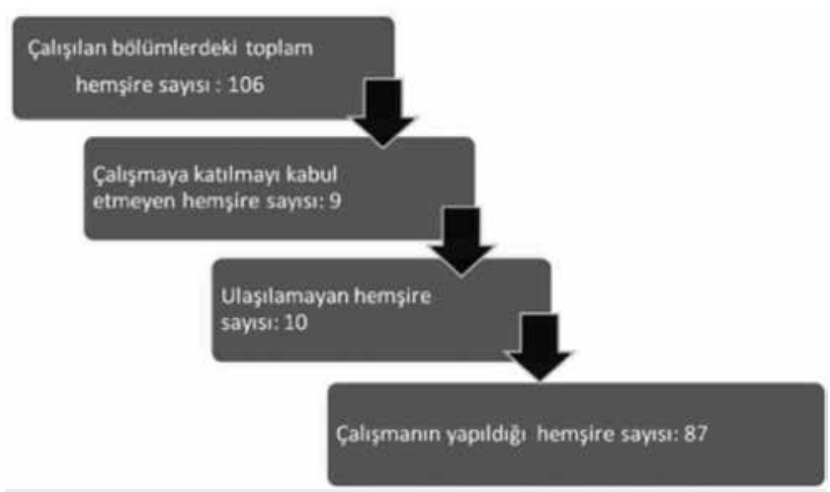

Şekil 1: Çalışmaya katılanların akış diyagramı

Tablo 1: Çalışmaya katılanların demografik özelliklerinin dağılımı

\begin{tabular}{lc}
\hline Demografik Özellikler & $\mathbf{n}(\%)$ \\
\hline $\begin{array}{l}\text { Yaş dağılımı, yıl } \\
\text { Çalışılan bölüm }\end{array}$ & $27.1 \pm 4.8$ \\
$\quad$ Yenidoğan Kliniği & \\
$\quad$ Çocuk Cerrahisi Kliniği & $73(83.9)$ \\
Toplam çalışma süresi & $14(16.1)$ \\
$<2$ yıl & \\
$2-5$ yıl & $15(17.2)$ \\
$5-10$ yıl & $36(41.4)$ \\
$>10$ yıl & $25(28.7)$ \\
Yenidoğan bölümünde çalışma süresi & $11(12.7)$ \\
$<2$ yıl & \\
$2-5$ yıl & $33(37.9)$ \\
$5-10$ yıl & $26(29.9)$ \\
$>10$ yıl & $21(24.1)$ \\
Eğitim durumu & $7(8.1)$ \\
Lise & \\
Önlisans & $16(18.4)$ \\
Lisans & $12(13.8)$ \\
Yüksek Lisans & $45(51.7)$ \\
Fototerapi hakkında klinik içi eğitim alma durumu \\
Evet & $14(16.1)$ \\
Hayır & $50(57.5)$ \\
\end{tabular}

mesi (\%88.5), beslenmenin iyi olmaması (\%85.1) ve sarılığın 2 haftadan uzun sürmesi (\%83.9) oranlarında doğru biliniyordu. Sarılığın tespit edilme yöntemi ile ilgili sorumuzda; önce yüzüne sonra gözler ve göğsüne bakarım (\%21.2), kan bilirubin seviyesine bakarım (\%58.6) ve burun ya da karın cildine bastırılıp kaldırıldığında sarı renk ile değerlendiririm (\%20.2) şeklinde yanıtlar alındı.

Sarılık tedavisinde kullanılan yöntemler nelerdir? sorusuna; fototerapi \%100, kan değişimi \%50.6 ve intravenöz immunglobulin \%11.4 oranında cevap verildi. Çalışılan ünitede kullanılan fototerapi şekilleri LED (Light Emitting Diode) fototerapi \%86.2, konvansiyonel fototerapi \%2.3 ve her ikisi \%11.5 oranlarındaydı. Hiperbilirubineminin sistemik bulguları içerisinde skleranın sarı olması \%86.4, cildin sarı olması \%80.7, hipoaktivite $\% 77$, emmede isteksizlik \%85.1, uykuya eğilim \%87.4 ve konvülziyon \%64.4 oranlarında doğru biliniyordu. Erken anne sütü sarılığının tanımı \%10.3 ve anne sütü sarılığı sendromunu tanımı \%16.1 oranında doğru bilindiği belirlendi. Fototerapinin etkinliğini artırma yöntemleri içerisinde doğru cevap sıklığı; verilen ışığın dozu \%88.5, ışık kaynağının enerji çıkışı \%42.5, ışık kaynağının sayısı \%81.6, ışık kaynağının bebeğe uzaklığı \%92 ve ışık alabilen maksimum cilt alanının genişliği \%93.1 oranındaydı. Bebeklerde sarılık tedavisinde uygulanan fototerapinin yan etkisi olarak; dehidratasyon, deri yanıkları, döküntü, bronz bebek gelişimi ve trombositopeni gelişebileceğini bilme oranı \%42.6 oranındaydı.

Fototerapi tedavisi esnasında hemşirelik bakım esasları içerisinde bebeklerin gözlerinin maske ile kapatılması gerektiği \%56.3, vücut ısısının 3 saat ara-

Tablo 2: Ankete katılanların fototerapi ile ilgili soruları doğru bilme oranları

\begin{tabular}{lc}
\hline Fototerapi ile ilgili sorular & Doğru bilme oranları \\
\hline Sarılık risk faktörlerini bilme & $\% 79.3$ \\
Sarıı̆ın uygun şekilde tespit edilmesi & $\% 58.6$ \\
Patolojik sarılığın tanımlanması & $\% 73.1$ \\
Sarı̆ı̆ın klinik bulgularının bilinmesi & $\% 61.3$ \\
Fototerapi etkinliği artırma yöntemlerinin bilinmesi & $\% 79.6$ \\
Fototerapi hemşirelik bakım esasları & $\% 52.9$ \\
Fototerapi yan etkilerinin doğru bilinmesi & $\% 42.6$ \\
Fototerapi esnasındaki beslenme yönetimi & $\% 65.6$ \\
Fototerapi cihazı - hasta uzaklığı mesafesinin bilinmesi & $\% 42.5$
\end{tabular}


lıklarla kontrolü \%57.5, insensibl sıvı kaybını takip edebilmek ve önleyebilmek için bebekler günde en az bir kez tartılması gerekliliği \%54, fototerapi alan bebeğin 3 saatlik aralarla pozisyonunun değiştirilmesi gerektiği \%54 ve bebekten kan alınırken fototerapi lambaları söndürülmesi gerektiği \%52.9 oranında doğru bilindiği saptandı.

Konvansiyonel fototerapi cihazının bebekten olması gereken $30-40 \mathrm{~cm}$ uzaklığı bilme oranı \%42.5 olarak belirlendi. Yüksek sarılık düzeyi ve emmeme sorunu ile yatırılan bir bebeği nasıl beslersiniz? sorusunda doğru şık olarak orogastrik sonda ile beslerim yanıtı \%46 oranında iken; anneyi emzirtirim, intravenöz sıvı veririm, biberonla kendim beslerim cevabını verenlerin toplam oranı \%54 idi.

Eğitim durumunun, doğru cevap oranları ile yapılan istatistiksel değerlendirmede yüksek lisans mezunlarının anne sütü sarılığı sendromunu doğru tanımlamada (p:0.05) ve erken anne sütü sarılığını bilmede (p:0.018) daha başarılı oldukları saptandı. Fototerapi hemşirelik bakım esaslarının lise mezunu olan grupta anlamlı olarak daha az bilindiği belirlendi ( $p: 0.004)$. Diğer tüm sorularda eğitim durumunun anlamlı bir istatistiksel etkisi saptanmadı.

Yenidoğan bölümünde çalışma süresinin etkisi incelendiğinde 10 yıldan fazla çalışan grupta cilt altı kanama, hematomun sarılık gelişiminde risk faktörü olduğunu bilme anlamlı olarak daha yüksekti (p:0.036). Yenidoğan bölümünde 5 yıldan fazla çalışanlarda anne sütü sarılığı sendromunu doğru tanımlama (p:0.048), erken anne sütü sarılığını bilme (p:0.002) ve fototerapinin yan etkilerini bilme (p:0.039) oranları daha yüksekti.

\section{TARTIŞMA}

Günümüzde gerek zamanında doğan gerekse erken doğan bebeklerde sıklıkla gelişen yenidoğan sarılığı önemli bir sorun olarak devam etmektedir $(5,6)$. Çalışmalarda, erken taburcu edilen bebeklerde hastaneye tekrar yatışların en sık sebebini hiperbilirubinemi oluşturmaktadır $(7,8)$. Yenidoğan bakımı ile ilgilenen hemşirelerin sarılık ve sarılık tedavisinde uygulanan fototerapi uygulaması ile ilgili uygulama durumlarını değerlendiren anket çalışmamızda; hem- şirelerin sarılığın klinik bulgularını, sarılık gelişimindeki risk faktörlerini, fototerapinin etkinliğini artırma yöntemlerini ve fototerapi esnasında beslenme yöntemlerini önemli bir oranda doğru olarak bildiğini, ancak fototerapinin yan etkilerini bilme ve konvansiyonel fototerapi cihazı ile bebek arasındaki mesafeyi doğru bilme oranlarının düşük olduğu belirlendi. Yüksek lisans eğitimi alan veya 5 yıldan daha uzun süre yenidoğan bölümünde çalışan hemşirelerin uygulama bilgilerinin daha yüksek oranda doğru olduğu saptandı.

Yenidoğan hemşirelerinin etkili hemşire bakımı ve fototerapi uygulamalarının doğru şekilde yapılmasının fototerapi etkinliğini artıracağı ve komplikasyonlarını en aza indireceği bildirilmektedir (4). Ülkemizde yenidoğan hemşireliğinin tanımı hemşirelik yönetmeliğinde şöyle ifade edilmektedir. Yenidoğan hemşiresi; profesyonel hemşirelik rolleri doğrultusunda yenidoğan ve yenidoğan yoğun bakım ünitesinde yatan bebeklerin; dış ortama uyumunun sağlanması, sağlıklı büyüme ve gelişmesi, anne sütü ile beslenmesi, hastalıklardan korunması ve sağlığının en üst düzeyine çıkarılmasında önemli rolleri olan; hastalandığında bakımından sorumlu olduğu bebeği kapsamlı olarak değerlendirip klinik belirti ve bulguları yorumlayabilen, ailesi ile birlikte değerlendiren, yenidoğanın bakım gereksinimlerini tespit ederek kanıta dayalı bilgiler doğrultusunda uygun bakımı planlayabilen, ünitedeki araç-gereçleri kullanabilen, araçlardaki verileri değerlendirip yorumlayabilen, bebekler ve yakınları ile iletişimi ve onlara uygun terapötik yaklaşım kurabilen, eğitim ve danışmanlık yapabilen ve ekip anlayışı içinde, ekip üyeleri ile iyi iletişim ve işbirliği kurma becerisine sahip hemşiredir (9). Sarılık ve fototerapi alan bebekler için bu yönetmelik değerlendirildiğinde, yenidoğan hemşiresinin sarılık nedeniyle yatan bebeklere uygulanan fototerapi tedavisinin nasıl yapıldığı, olası komplikasyonlarını, cihazların özelliklerini ve beslenme şekillerini doğru bilmesi gerekir. Yenidoğan hemşirelik hizmetleri içerisinde klinik içi eğitimlerde sarılıklı bebeğin bakımı, sarılığın bulguları, fototerapi uygulama yöntemleri ve fototerapi ile görülebilen komplikasyonlar ile ilgili sürekli bir eğitim almaları gerektiği belirlendi.

Sonuç olarak yenidoğan hemşirelerinin sarılık ve 
fototerapi uygulamaları ile ilgili uygulama durumları$\mathrm{nı}$ inceleyen ülkemizde ilk kez planlanan çalışmamızda, yenidoğan bölümünde 5 yıldan daha uzun süre çalışan hemşirelerin uygulama bilgilerinin daha

\section{KAYNAKLAR}

1. Bülbül A, Okan F, Uslu S, İş̧̧i E, Nuhoğlu A. term bebeklerde hiperbilirubineminin klinik özellikleri ve risk etmenlerinin araştırılması. Türk Pediatri Arşivi 2005; 40: 204-10.

2. Bülbül A, Okan F, Ciğerci N, Nuhoğlu A. Hiperbilirubinemi nedeniyle kan değişimi uygulanan zamanında doğmuş bebeklerin klinik özellikleri ve kan değişimi nedenleri. Türk Ped Arş 2007; 42: 107-11.

3. Açık Y, Deveci SE, Ulutaşdemir N, ipekçi N. Yenidoğan sarılığı ve aile eğitimi. Fırat Sağlık Hizmetleri Dergisi 2010; 13: 61-72.

4. Canbulat N, Demirgöz M. Yenidoğanın ışık tedavisi: fototerapi. Zeynep Kamil Tıp Bülteni 2009; 1: 37-41.

5. Çayönü N, Bülbül A, Uslu S, Bolat $F$, Güran Ö, Nuhoğlu A. Yenidoğan bebeklerde son on yılda indirect hiperbilirubinemi değişimi. ŞEEAH Tıp Bülteni 2011; 45: 85-93. iyi olduğu belirlendi. Yenidoğan sağlığını sunan bölümlerde sarılık ve fototerapi uygulamaları ile ilgili sürekli olarak klinik içi eğitim verilmesi gerektiği belirlendi.

6. Bolat F, Uslu S, Bülbül A, Cömert S, Can E, Nuhoğlu A. Yenidoğan ünitemizde indirekt hiperbilirubinemi tanısı ile yatırılan term yenidoğan bebeklerin değerlendirilmesi. Çocuk Dergisi 2010; 10: 69-74.

7. Akın MA, Kavuncuoğlu S. Erken taburcu olan yenidoğanlarda yeniden hastaneye yatış nedenleri ve sonuçları. Türk Pediatri Arşivi 2006; 41: 201-7.

8. Maisels M, Kring E. Length of stay, jaundice, and hospital readmission. Pediatrics 1998; 101; 995-8.

9. Hemşirelik Yönetmeliğinde Değişiklik Yapılmasına Dair Yönetmelik; resmi gazete 19 Nisan 2011 sayı: 27910. 